\title{
Systematic analysis of tumour cell-extracellular matrix adhesion identifies independent prognostic factors in breast cancer
}

\author{
Jason R. Todd ${ }^{1, *}$, Karen A. Ryall ${ }^{2, *}$, Simon Vyse ${ }^{1, *}$, Jocelyn P. Wong ${ }^{1}$, Rachael C. \\ Natrajan ${ }^{3,4}$, Yinyin Yuan ${ }^{4}$, Aik-Choon Tan ${ }^{2}$ and Paul H. Huang ${ }^{1}$ \\ ${ }^{1}$ Division of Cancer Biology, The Institute of Cancer Research, London, UK \\ ${ }^{2}$ Department of Medicine, Translational Bioinformatics and Cancer Systems Biology Laboratory, Division of Medical Oncology, \\ University of Colorado Anschutz Medical Campus, Aurora, CO, USA \\ ${ }^{3}$ The Breast Cancer Now Toby Robins Research Centre, Division of Breast Cancer Research, The Institute of Cancer Research, \\ London, UK \\ ${ }^{4}$ Division of Molecular Pathology, The Institute of Cancer Research, London, UK \\ * These authors have contributed equally to this work
}

Correspondence to: Paul H. Huang, email: paul.huang@icr.ac.uk

Keywords: cell adhesion, breast cancer, extracellular matrix, laminin, HER2

Received: March 22, 2016

Accepted: July 27, 2016

Published: August 17, 2016

\section{ABSTRACT}

Tumour cell-extracellular matrix (ECM) interactions are fundamental for discrete steps in breast cancer progression. In particular, cancer cell adhesion to ECM proteins present in the microenvironment is critical for accelerating tumour growth and facilitating metastatic spread. To assess the utility of tumour cell-ECM adhesion as a means for discovering prognostic factors in breast cancer survival, here we perform a systematic phenotypic screen and characterise the adhesion properties of a panel of human HER2 amplified breast cancer cell lines across six ECM proteins commonly deregulated in breast cancer. We determine a gene expression signature that defines a subset of cell lines displaying impaired adhesion to laminin. Cells with impaired laminin adhesion showed an enrichment in genes associated with cell motility and molecular pathways linked to cytokine signalling and inflammation. Evaluation of this gene set in the Molecular Taxonomy of Breast Cancer International Consortium (METABRIC) cohort of 1,964 patients identifies the F12 and STC2 genes as independent prognostic factors for overall survival in breast cancer. Our study demonstrates the potential of in vitro cell adhesion screens as a novel approach for identifying prognostic factors for disease outcome.

\section{INTRODUCTION}

The extracellular matrix (ECM) in the mammary gland microenvironment undergoes dynamic remodelling and is deregulated during breast cancer progression [1,2]. By providing adhesive surfaces that promote adhesome complex formation and the activation of intracellular signalling [3, 4], ECM proteins have been shown to accelerate tumour progression and metastatic disease in breast cancer [5-8]. Degradation of the basement membrane (BM), which is primarily composed of ECM components collagen IV and laminin, is also required for cancer cell invasion into the surrounding blood vessels and lymphatics facilitating metastatic spread [9]. Given the important contributions of the ECM in breast cancer biology, protein expression levels of specific ECM components such as fibronectin and tenascin $\mathrm{C}$ are known prognostic markers for poor overall patient survival [1012]. More broadly, multiple studies demonstrate that gene expression signatures of the breast cancer stroma encompassing ECM proteins are more robust predictors of patient outcome than those of the tumour epithelial [13$16]$.

While critical for promoting cancer progression, tumour cell-ECM interactions are challenging to study due to the dynamic remodelling of the matrisome in vivo [17], the wide array of ECM receptors expressed in cells [18] and the ability of these receptors to synergistically 
interact in a complex non-intuitive fashion [19, 20]. The multi-factorial nature of these interactions is one reason why targeting ECM receptors, while conceptually attractive, has yet to translate into successful clinical candidates for cancer therapy [21]. To address some of these challenges, large-scale ECM arrays have been developed to examine tumour cell-ECM interactions in a systematic and combinatorial manner [20]. This has led to the characterisation of key adhesive changes associated with metastatic progression in a mouse model of lung adenocarcinoma and provided the first demonstration that in vitro cell adhesion screens can be employed as a means to identify clinically meaningful biomarkers such as galectin-3 for tumour, node and metastasis (TMN) staging [20].

The prognostic value of cancer cell adhesion has remained unexplored and we hypothesize that in addition to tumour staging, analysis of tumour cell-ECM interactions may reveal new prognostic factors for disease outcome. To investigate the relationship between tumour cell-ECM interactions and breast cancer survival, in this study we undertook an automated image-based phenotypic screen to assess tumour cell-ECM adhesion profiles in a panel of HER2-amplified (HER2+) breast cancer cell lines. We identified a gene expression signature that defines breast cancer cell lines with impaired adhesion to laminin and correlate these findings with a clinical dataset of 1,964 breast cancer cases to isolate genes that are prognostic for overall survival in patients. Our study demonstrates that cell adhesion screens have the potential to identify novel prognostic factors in breast cancer and is a general approach that can be readily extended to the study of other tumour types.

\section{RESULTS}

\section{Analysis of tumour cell-ECM interactions reveals a subset of cell lines that display impaired adhesion to laminin}

To systematically characterise tumour cell-ECM interactions in breast cancer, we utilised a panel of seven well-annotated HER2+ breast cancer cell lines [22, 23]. HER2 overexpression or amplification is present in $\sim 20 \%$ of breast cancers and is associated with poor prognosis and aggressive disease [24]. We employed automated image-based phenotypic screens to evaluate the manner in which HER2+ cells adhere to ECM molecules. 96-well

A

0
0
0
$\frac{\pi}{2}$
0
0
0
0
0
0
$\frac{0}{0}$
5
5
0
5
+
5
5
0
0
$\frac{1}{0}$
$\frac{0}{0}$
5
$z$

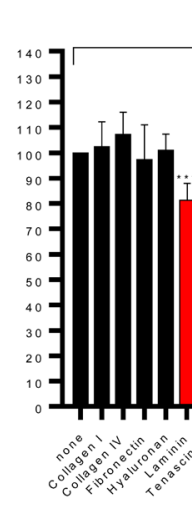

Impaired Lam in in Adhesion
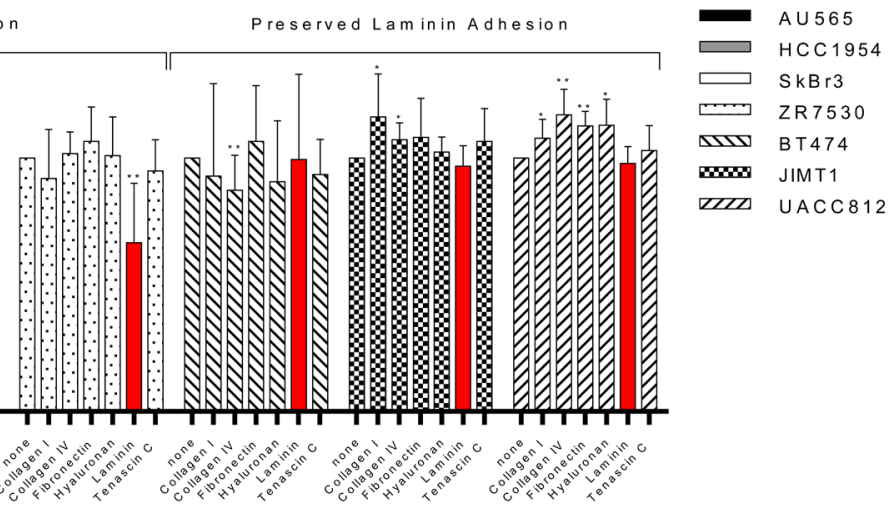

B
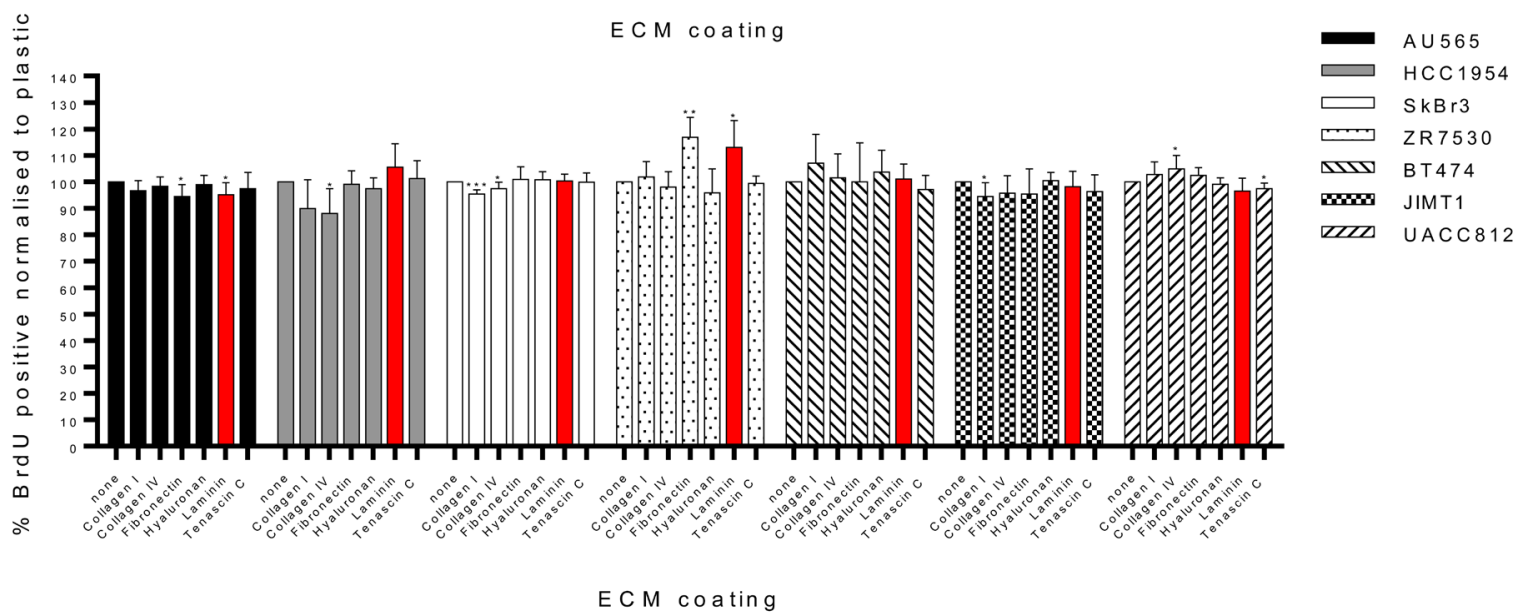
C

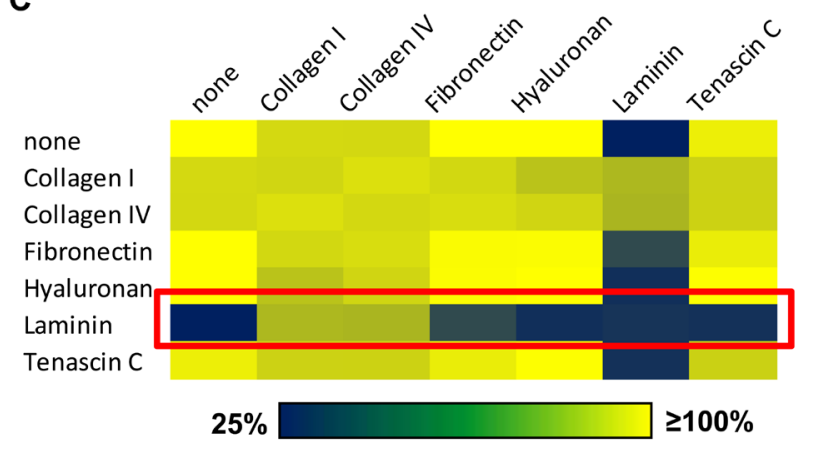

E

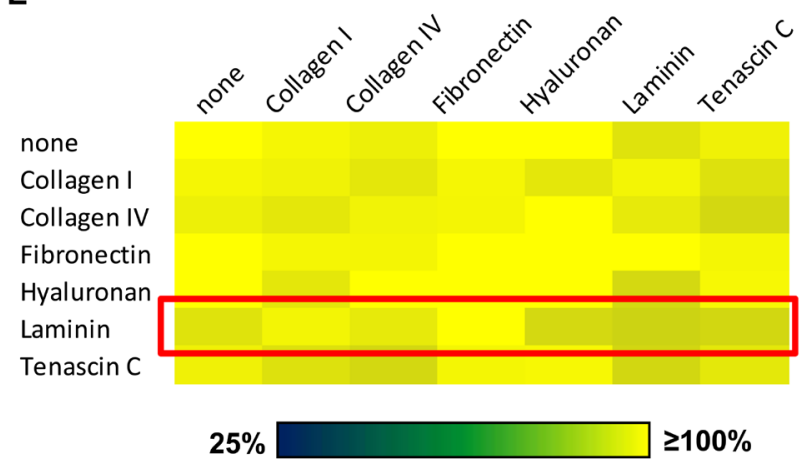

D

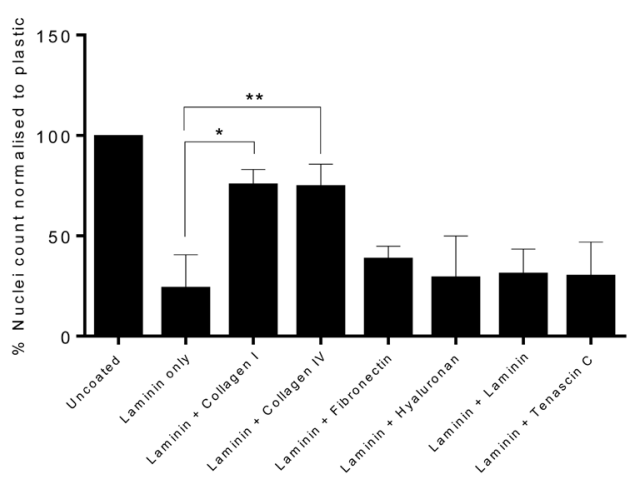

$\mathbf{F}$

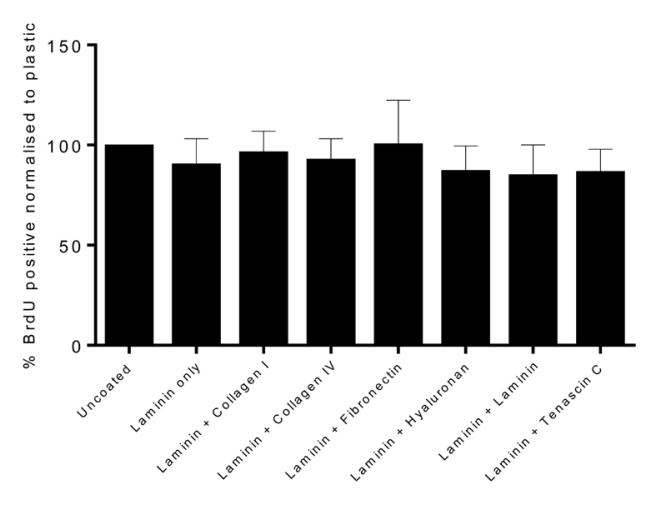

ECM coating

Figure 1: A subset of breast cancer cell lines display impaired adhesion of laminin. Bar plots showing percentage A. DAPI stained nuclei counts or B. BrdU incorporation in a panel of seven HER2+ breast cancer cell lines on six ECM substrates. Data is normalised to the plastic control ( $n=7$ or 8). Statistical analysis comparing ECM substrate versus plastic control was performed by paired Student's $\mathrm{t}$ test where ${ }^{*} p<0.05,{ }^{* *} p<0.01$ and ${ }^{* * *} p<0.001$. All values are mean $\pm \mathrm{SD}$. C. Heatmap of percentage nuclei counts as measured by DAPI staining in the $\mathrm{SkBr} 3$ cell line in the presence of pairwise combinations of ECM substrates. Red box highlights combination of laminin with other ECM substrates. D. Bar plots of percentage nuclei counts in $\mathrm{SkBr3}$ cells under conditions of pairwise combinations of laminin and an additional ECM substrate. Data is normalised to uncoated plastic control $(n=3)$. Statistical analysis of combined ECM substrate versus laminin only was performed by paired Student's $t$ test where ${ }^{*} p<0.05$ and ${ }^{* *} p<0.01$. All values are mean \pm SD. E. Heatmap of percentage BrdU incorporation in the $\mathrm{SkBr} 3$ cell line in the presence of pairwise combinations of ECM substrates. Red box highlights combination of laminin with other ECM substrates. F. Bar plots of percentage BrdU incorporation in $\mathrm{SkBr} 3$ cells under conditions of pairwise combinations of laminin and an additional ECM substrate. Data is normalised to uncoated plastic control $(n=3)$. All values are mean \pm SD.

plates were pre-coated with six ECM components that are commonly deregulated in breast cancer (collagen I, collagen IV, fibronectin, hyaluronan, laminin, tenascin C) with uncoated plastic as a negative control [25]. Cells were subsequently seeded and screened for cell adhesion at 72 hours using DAPI as a nuclei stain (Figure 1).

Mining the phenotypic dataset, we identified a subset of cell lines (AU565, HCC1954, SkBr3 and ZR75.30) that displayed significantly impaired cell adhesion when seeded on laminin (Figure 1A). The remaining three cell lines BT474, JIMT1 and UACC812 showed normal adhesion to laminin versus plastic. To demonstrate that the observed decrease in nuclei counts is not the result of reduced cell proliferation in response to ECM exposure, we assessed BrdU incorporation in the cell line panel on the 6 ECM substrates (Figure 1B). ECM substrates did not reduce cell proliferation across the panel of cell lines while increased proliferation was only found in the ZR75.30 cells when exposed to fibronectin and laminin. These data confirm that the observed decrease in nuclei count in AU565, HCC1954, SkBr3 and ZR75.30 cell lines is due to a reduction in cell adhesion on laminin rather than a decrease in proliferative rate.

\section{Combinations of collagens with laminin rescues SkBr3 cell adhesion}

A previous unbiased screen of lung adenocarcinoma cell-ECM adhesion showed that distinct combinations of ECM substrates results in unanticipated additive, 
Table 1: Correlation of $\mathrm{mRNA}$ levels of ECM receptors and cell adhesion

\begin{tabular}{|c|c|c|c|}
\hline ECM & Receptor & R (Correlation coefficient) & $P$-value \\
\hline \multirow{7}{*}{ Collagen I } & ITGA1 & 0.46 & 0.30 \\
\hline & ITGA2 & 0.22 & 0.64 \\
\hline & ITGA10 & 0.08 & 0.86 \\
\hline & DDR1 & 0.47 & 0.29 \\
\hline & DDR2 & 0.16 & 0.73 \\
\hline & ITGAX & -0.19 & 0.68 \\
\hline & ITGB1 & 0.32 & 0.48 \\
\hline \multirow{5}{*}{ Collagen IV } & ITGA1 & 0.49 & 0.26 \\
\hline & ITGA2 & 0.07 & 0.87 \\
\hline & ITGA10 & 0.48 & 0.27 \\
\hline & ITGB1 & 0.14 & 0.76 \\
\hline & DDR1 & 0.88 & $0.01 *$ \\
\hline Hyaluronan & CD44 & 0.31 & 0.50 \\
\hline \multirow{8}{*}{ Laminin } & ITGA1 & 0.13 & 0.78 \\
\hline & ITGA2 & 0.31 & 0.49 \\
\hline & ITGA3 & 0.46 & 0.30 \\
\hline & ITGA6 & 0.45 & 0.30 \\
\hline & ITGA7 & 0.00 & 0.99 \\
\hline & ITGA10 & -0.21 & 0.65 \\
\hline & ITGB1 & 0.62 & 0.14 \\
\hline & ITGB4 & 0.10 & 0.83 \\
\hline \multirow{11}{*}{ Fibronectin } & ITGA4 & -0.17 & 0.72 \\
\hline & ITGA5 & 0.08 & 0.86 \\
\hline & ITGA8 & -0.64 & 0.12 \\
\hline & ITGAV & -0.52 & 0.23 \\
\hline & ITGA2B & 0.37 & 0.42 \\
\hline & CD44 & 0.40 & 0.37 \\
\hline & ITGB1 & 0.79 & $0.04 *$ \\
\hline & ITGB3 & 0.11 & \begin{tabular}{|l|}
0.82 \\
\end{tabular} \\
\hline & ITGB6 & -0.10 & 0.82 \\
\hline & ITGB7 & -0.56 & 0.19 \\
\hline & ITGB8 & -0.20 & 0.66 \\
\hline \multirow{5}{*}{ Tenascin C } & ITGA8 & -0.26 & 0.57 \\
\hline & ITGAV & 0.31 & 0.50 \\
\hline & ITGB1 & 0.70 & 0.08 \\
\hline & ITGB3 & -0.28 & 0.54 \\
\hline & ITGB6 & 0.40 & 0.37 \\
\hline
\end{tabular}

* Statistical significance of correlation where $p<0.05$.

synergistic or antagonistic effects on cell adhesion [20]. We sought to determine if similar effects were present in breast cancer, using the laminin adhesion impaired $\mathrm{SkBr} 3$ cell line as a model. These cells were subjected to pairwise combinations of the 6 ECM substrates and plastic for 72 hours prior to assessment for nuclei counts. This screen revealed that both collagen I and collagen IV were able to rescue the impaired tumour cell adhesion when combined with laminin (Figure 1C \& 1D). Assessment of BrdU incorporation in the combination ECM format showed that there were no significant differences in proliferation across all laminin-ECM combinations, indicating that the observed rescue of cell adhesion in the presence of collagen was independent of cell proliferation (Figure 1E $\& 1 \mathrm{~F})$

Analysis of publically available transcriptional profiles of the seven cell lines finds that cell adhesion profiles on single ECMs had no correlation with the mRNA expression levels of their cognate laminin or collagen receptors such as the integrins (Table 1) [26, 27]. The exception is the positive correlation between collagen IV and Discoidin Domain Receptor 1 (DDR1) (correlation coefficient $R=0.88, p=0.01$ ). It should be noted that the data in Table 1 reflects the gene expression 
levels of these receptors at steady state in the breast cancer cell line panel and not in response to ECM exposure. Importantly we show by 2 -way clustering of mRNA levels of the laminin-binding integrins that there is no obvious correlation between laminin adhesion and integrin mRNA levels (Supplemental Figure 1A). For instance, HCC1954 has high levels of laminin-binding integrin mRNA levels but displays impaired adhesion. In
A Extracellular Matrix Pathway Genes

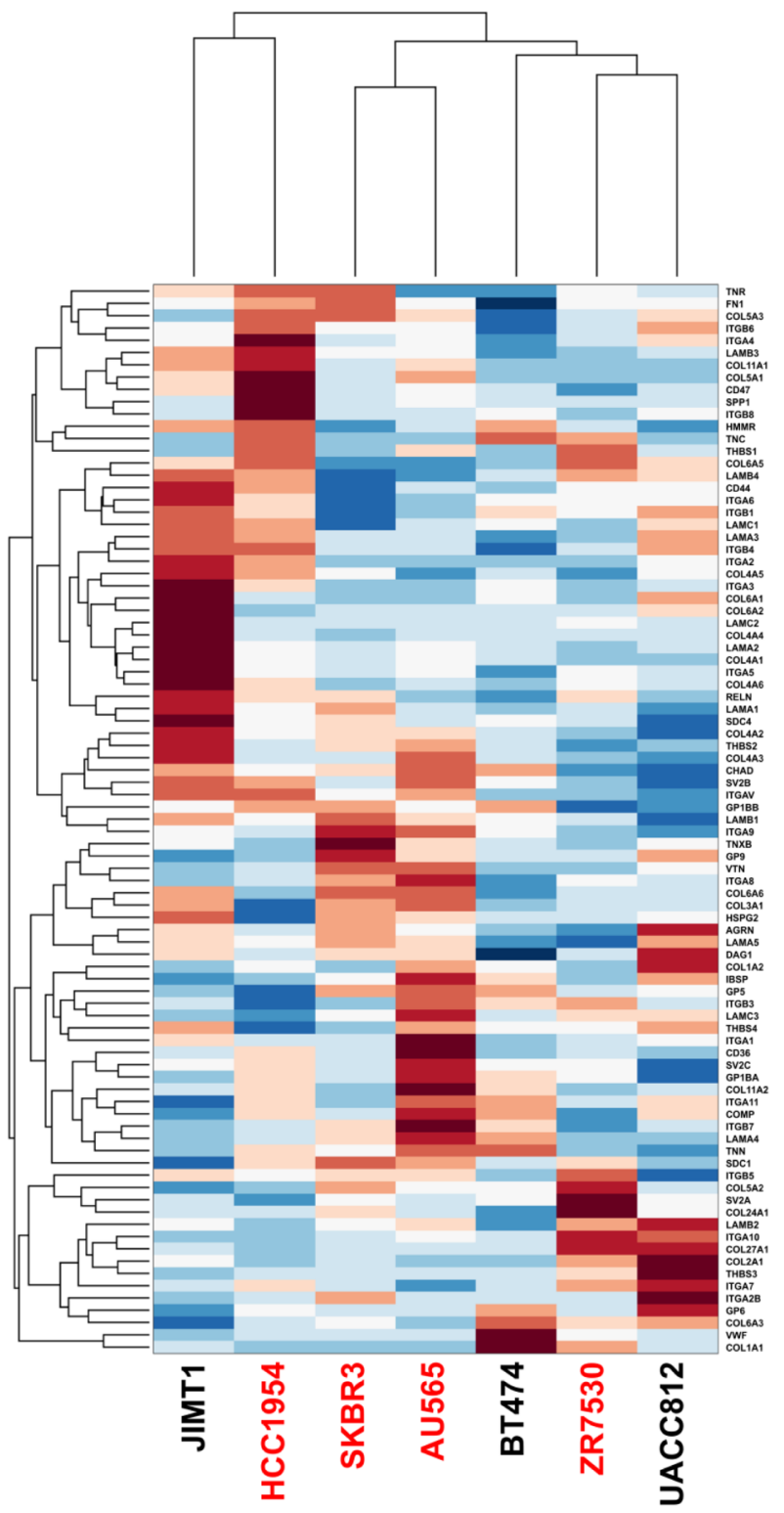

B

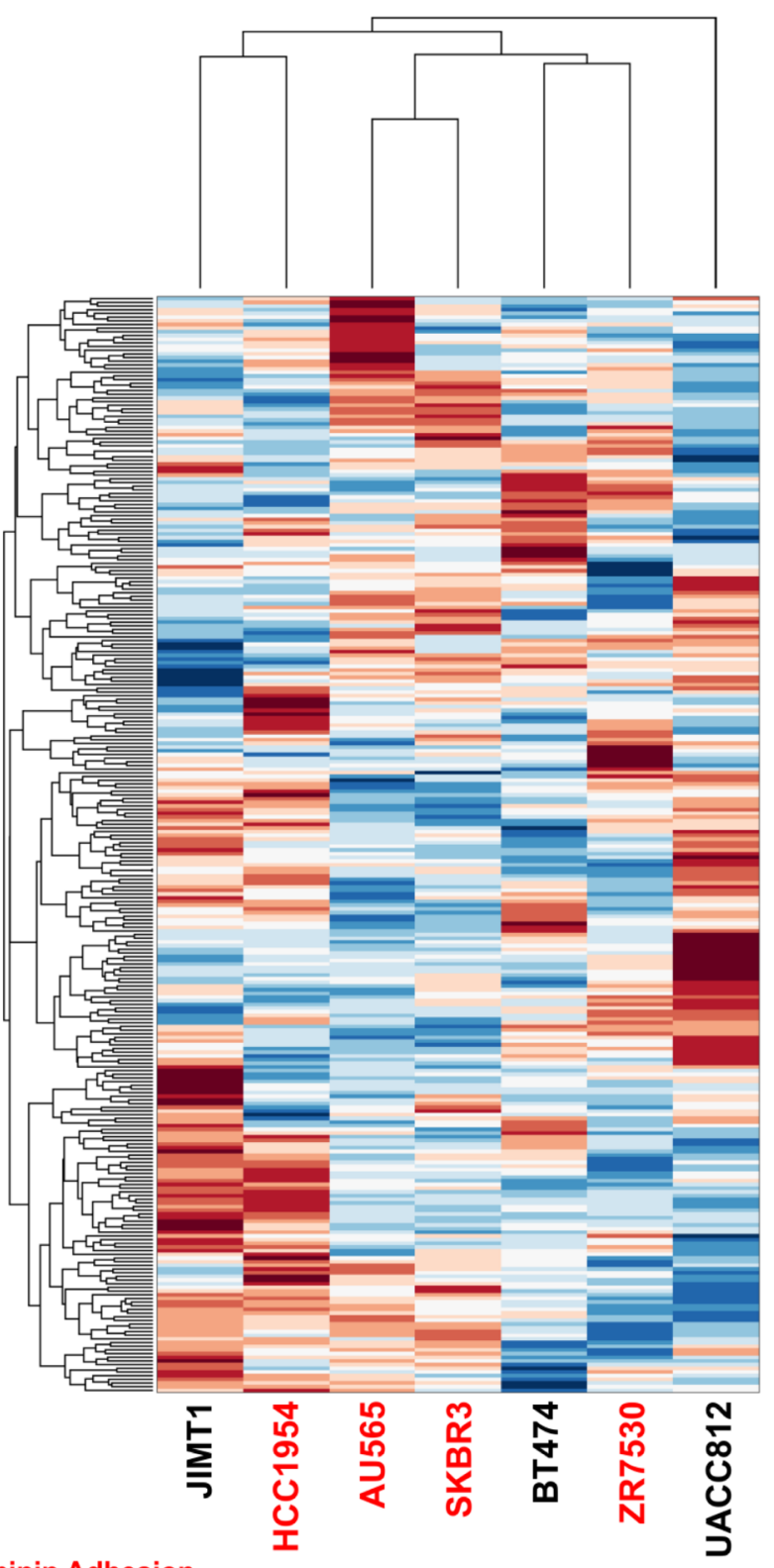

Impaired Laminin Adhesion

Preserved Laminin Adhesion

Figure 2: Impaired laminin adhesion cell lines do not cluster based on expression of specific ECM genes or kinases. Hierarchical clustering of normalised microarray gene expression data for A. KEGG annotated ECM pathway genes and B. kinases. Each row was normalised before clustering to give a mean of 0 and a standard deviation of 1 . Red indicated higher expression of a gene in the cell line and blue indicates lower expression. Cell lines with impaired laminin adhesion are labelled in red. 
addition, SkBr3 and BT474 are part of the same cluster despite displaying opposing laminin adhesion profiles. We have also performed a Student's t-test analysis comparing the laminin-binding integrin levels of both groups of cell lines (impaired laminin adhesion and preserved laminin adhesion) and show that there is no statistical difference in the integrin gene expression levels between the two groups (Supplemental Table 1).

To validate the observations identified in the microarray analysis, we performed real-time quantitative PCR measurements (RT-qPCR) of the laminin-binding integrins. Correlation analysis with laminin adhesion (Supplemental Table 2), 2-way clustering (Supplemental Figure 1B) and Student's t-test (Supplemental Table 1) of qPCR data confirms that there is no correlation between laminin adhesion and integrin mRNA levels. This data provides further evidence that gene expression levels of the integrins are not able to classify cells based on their
A

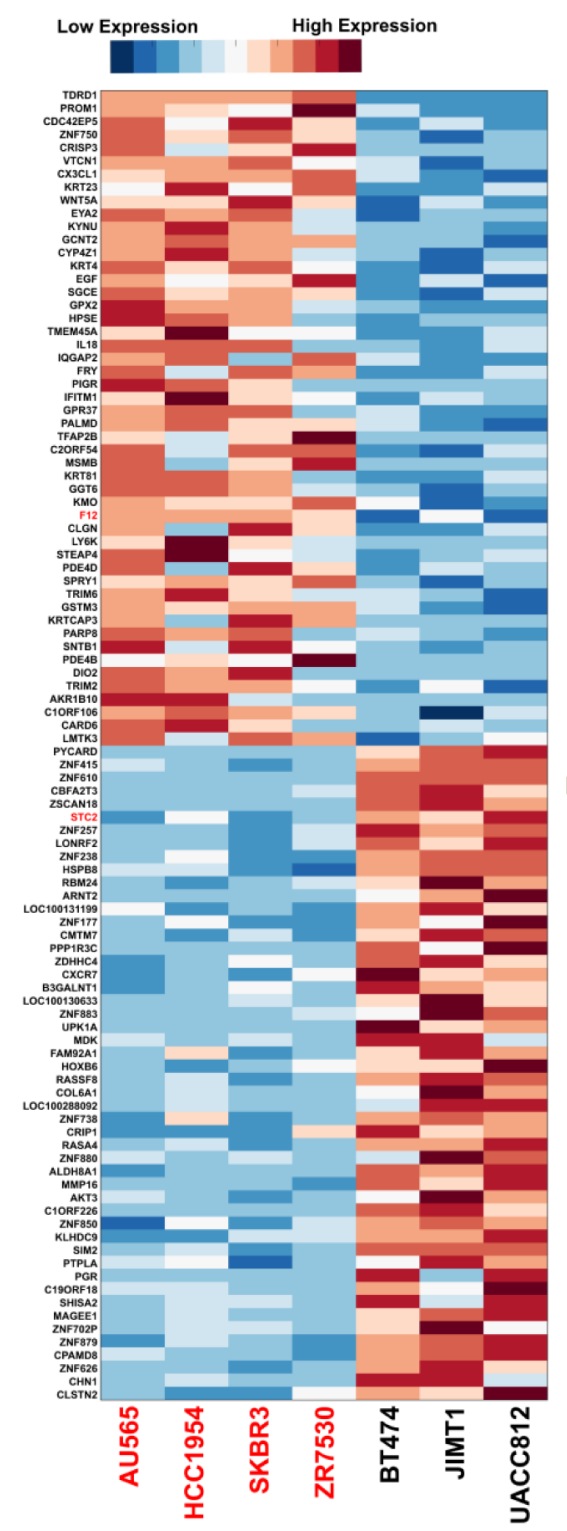

B

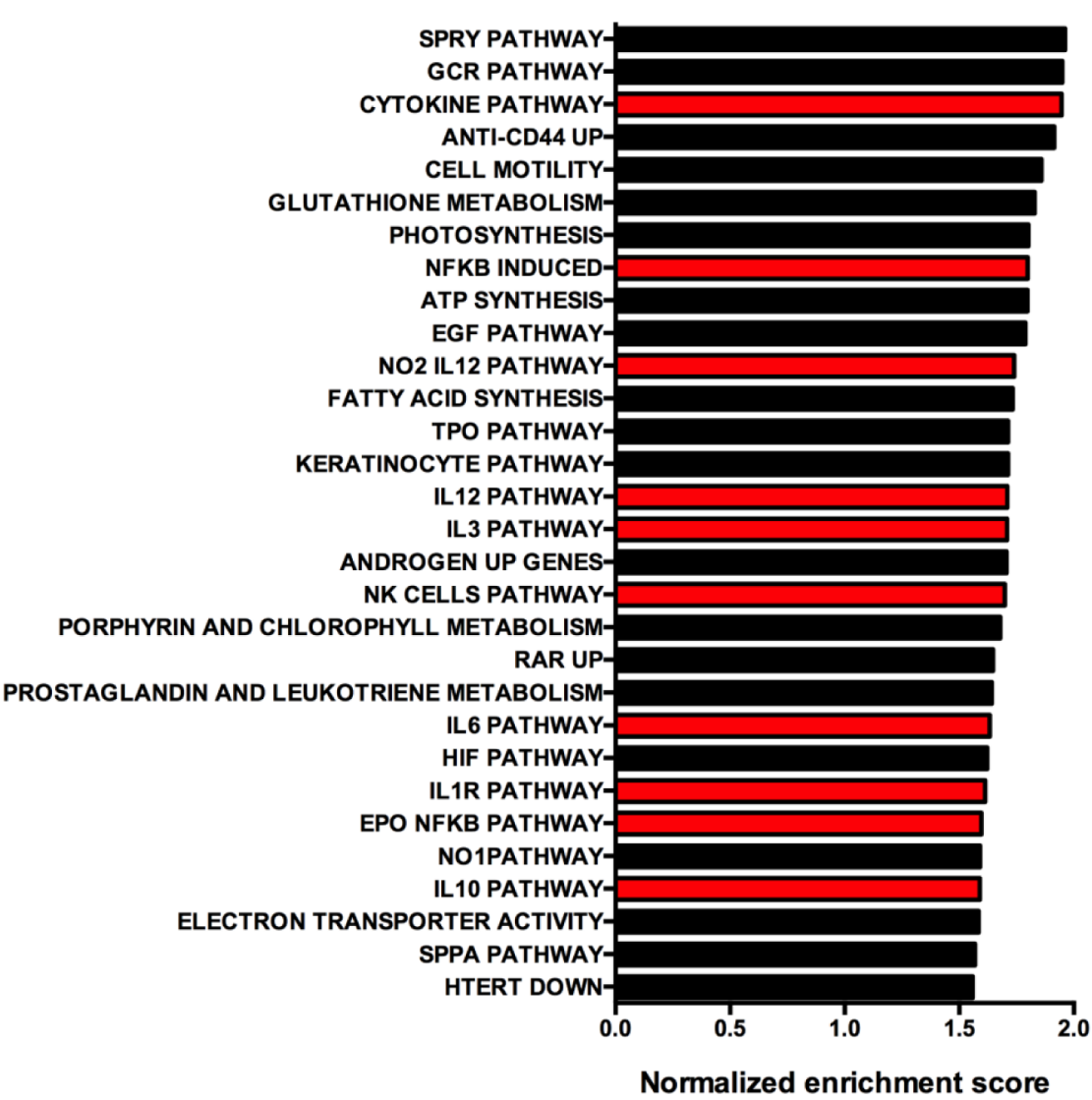

Normalized enrichment score

Figure 3: Genes that are correlated with impaired laminin adhesion. A. Gene expression heatmap for the top 50 genes positively and negatively correlated with the impaired laminin adhesion cell lines. Gene markers were identified using GSEA. Each row of the heatmap was normalized to give a mean of 0 and a standard deviation of 1 . Red indicates higher expression of a gene and blue indicates lower expression. FDR values for all 100 genes were calculated with $p$-values shown to be $<0.05$. B. Normalized enrichment scores for GSEA analysis of MSigDB curated pathways / gene sets enriched in the impaired laminin adhesion cell lines with nominal $p$-values $<0.05$. Bars highlighted in red are those pathways associated with cytokine signalling and inflammation. 
Table 2: Multivariate analysis of the prognostic value of F12 or STC2 for disease-specific survival in two cohorts of breast cancer patients.

\begin{tabular}{|c|c|c|c|c|}
\hline \multirow{2}{*}{ Variable } & \multicolumn{2}{|c|}{ Discovery Cohort $(n=985)$} & \multicolumn{2}{|c|}{ Validation Cohort $(n=979)$} \\
\hline & HR (95\% CI) & $p$ & HR (95\% CI) & $p$ \\
\hline F12 & $1.47(1.09-1.97)$ & $0.012 *$ & $1.53(1.13-2.08)$ & $0.0064 * *$ \\
\hline Node & $2.04(1.54-2.71)$ & $7.8 \times 10^{-7 * *}$ & $2.45(1.80-3.34)$ & $1.2 \times 10^{-8 * *}$ \\
\hline Size & $1.44(1.13-1.84)$ & $0.0034 * *$ & $1.57(1.23-2.00)$ & $0.00029 * *$ \\
\hline Grade & $1.36(1.05-1.75)$ & $0.018 *$ & $1.31(1.00-1.70)$ & $0.048 *$ \\
\hline HER2 & $1.63(1.17-2.28)$ & $0.0042 * *$ & $1.28(0.90-1.83)$ & 0.17 \\
\hline ER & $0.63(0.45-0.89)$ & $0.0084 * *$ & $0.55(0.39-0.77)$ & $0.00049 * *$ \\
\hline Age & $1(0.99-1.01)$ & 0.68 & $1.01(1.00-1.02)$ & 0.14 \\
\hline STC2 & $0.71(0.51-0.99)$ & $0.043 *$ & $0.51(0.35-0.75)$ & $0.00056^{* *}$ \\
\hline Node & $2.03(1.53-2.70)$ & $1.1 \times 10^{-6 * *}$ & $2.43(1.79-3.31)$ & $1.5 \times 10^{-8 * *}$ \\
\hline Size & $1.44(1.13-1.85)$ & $0.0036 * *$ & $1.57(1.23-2.00)$ & $0.00025 * *$ \\
\hline Grade & $1.31(1.01-1.70)$ & $0.039 *$ & $1.23(0.95-1.60)$ & 0.12 \\
\hline HER2 & $1.63(1.17-2.27)$ & $0.0041 * *$ & $1.29(0.91-1.82)$ & 0.16 \\
\hline ER & $0.73(0.51-1.03)$ & $0.071 *$ & $0.72(0.51-1.03)$ & 0.07 \\
\hline Age & $1(0.99-1.01)$ & 0.56 & $1.01(1.00-1.02)$ & 0.11 \\
\hline
\end{tabular}

ability to bind laminin. This finding is consistent with the previous tumour cell-ECM screen by Reticker-Flynn et al., which showed that unlike protein level measurements, mRNA levels of adhesion receptors are poor predictors of cell-ECM interactions [20].

\section{Identification of molecular pathways associated with impaired laminin adhesion}

To identify molecular pathways associated with impaired laminin adhesion, we mined publically available gene expression data for the cell line panel from the Cancer Cell Line Encyclopaedia (CCLE) [28]. We first examined the ECM pathway genes that are annotated in the Kyoto Encyclopaedia of Genes and Genomes (KEGG) and found that these genes were not able to distinguish cell lines that had impaired laminin adhesion (Figure 2A). Given that the panel of cell lines is driven by the HER2 tyrosine kinase and that the process of cell adhesion is propagated by kinase signalling networks [4], we sought to establish if RNA expression levels of kinases was capable of discriminating the two subsets of cells. An analysis of 298 genes from the kinome showed that kinase profiles have no correlation with the impaired laminin adhesion that was observed in the phenotypic screen (Figure 2B).

Unbiased analysis of the gene expression data revealed the top 50 genes, out of 21,009 genes incorporated into the analysis, that were positively and negatively correlated with impaired laminin adhesion in the cell line panel (Figure 3A). A selection of 15 genes from this signature was validated by RT-qPCR and show good concordance with the CCLE microarray data (Supplemental Table 3). Ontology analysis of genes that are upregulated in the cells with impaired laminin adhesion (AU565, HCC1954, SkBr3 and ZR75.30) using GSEA showed an enrichment of genes for cell motility (Figure 3B). Additionally, there was an unexpected enrichment of 
A

F12 Discovery

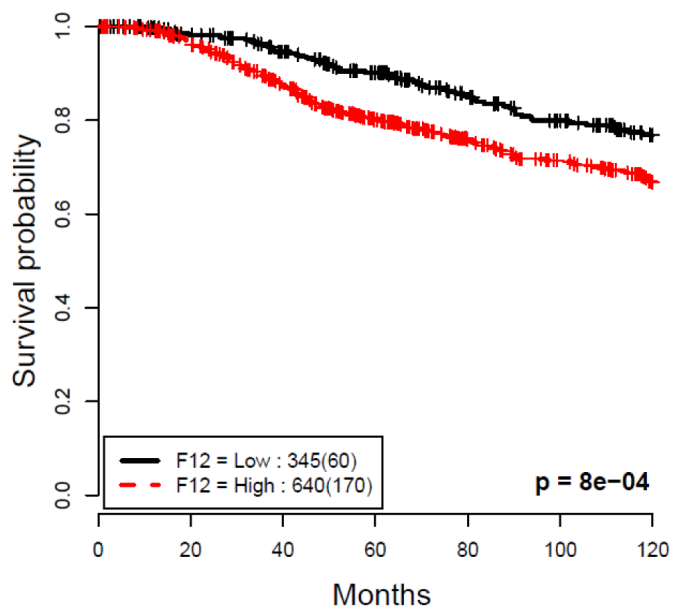

B

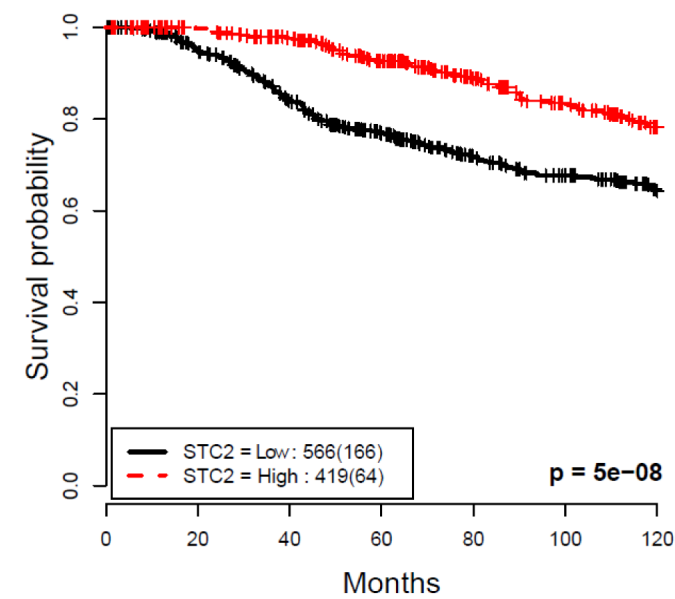

C

Combined Discovery

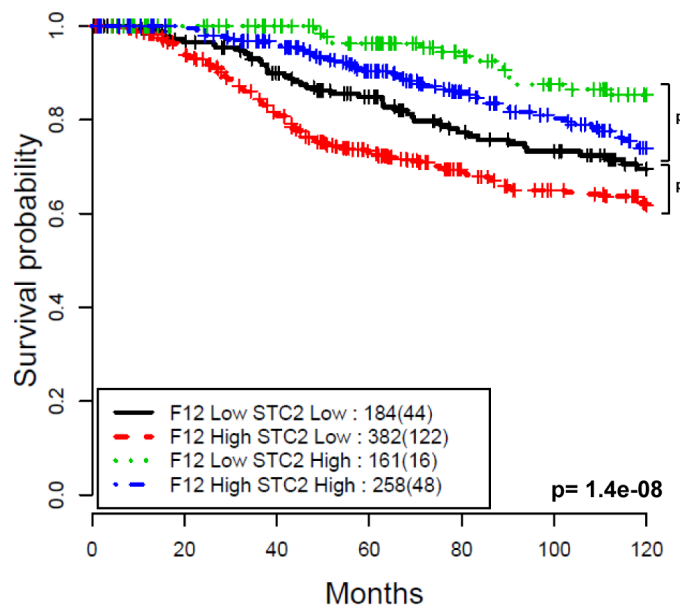

F12 Validation

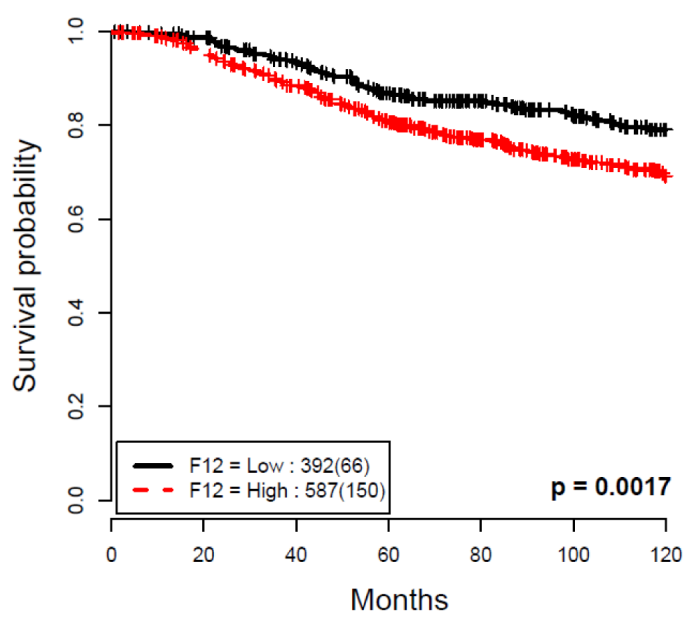

STC2 Validation

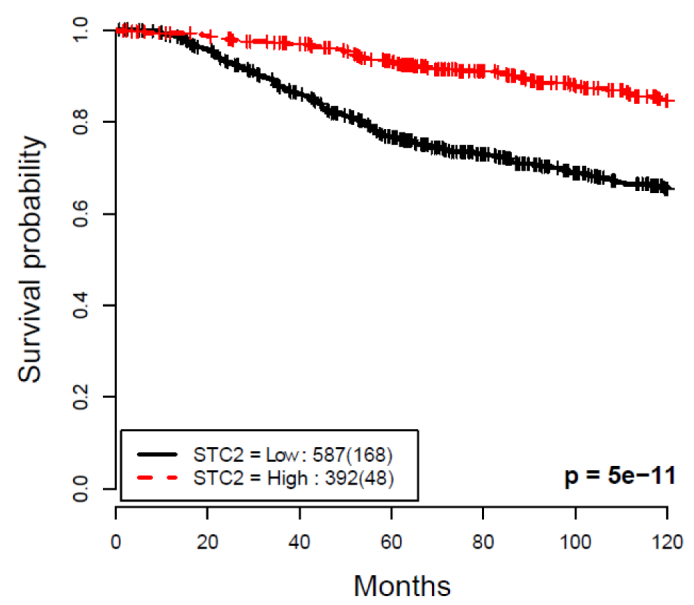

Combined Validation

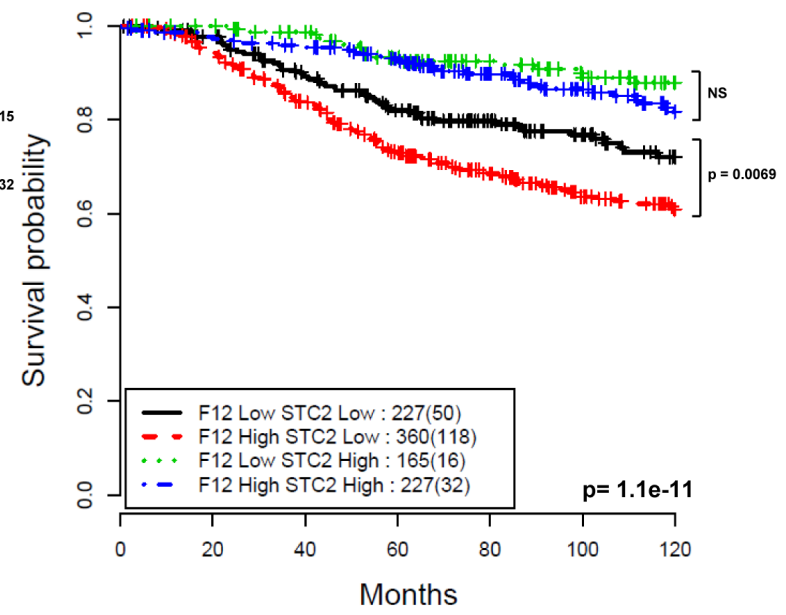

Figure 4: Association between F12 and STC2 gene expression and disease-specific survival in breast cancer. KaplanMeier curves illustrate differences in disease-specific survival in patient groups in two subsets stratified by A. F12, B. STC2 and C. F12 + STC2 gene expression levels. The thresholds for dichotomising two indices were optimised in the discovery cohort (left) and then used without modification in the validation cohort (right) ( 0.2718 for F12, 0.2801 for STC2). Numbers in the legend show the number of patients in each group and numbers in brackets show the number of disease-specific deaths. Log-rank test p-values show significant differences between F12-high/STC2-low and F12-low/STC2-low groups. NS is not significant. 
multiple gene sets associated with cytokine signalling and the inflammatory response. These included the cytokine

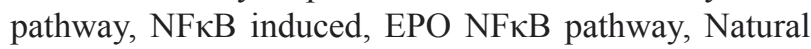
Killer (NK) cells pathway, Interleukin-1 receptor (IL1R), Interleukin-12 (IL12), Interleukin-10 (IL10), Interleukin-6 (IL6) and Interleukin-3 (IL3) pathways (Figure 4B). This analysis suggests that cytokine signalling may play a role in the modulation of cancer cell adhesion. Other important and well-characterised oncogenic pathways that were found to be enriched included the Epidermal Growth Factor Receptor (EGFR), Sprouty (SPRY) and Hypoxia Inducible Factor (HIF) signalling pathways.

\section{Impaired laminin adhesion identifies prognostic genes for breast cancer disease-specific survival}

Given the important functional roles of laminin in breast cancer progression and metastasis [29], we hypothesised that genes enriched in the subset of cell lines with impaired laminin adhesion may have prognostic value for disease outcome. We focused on the top 50 genes that were either positively or negatively correlated with impaired laminin adhesion (Figure 3A). The METABRIC (Molecular Taxonomy of Breast Cancer International Consortium) study is a molecular and pathological characterisation of almost 2000 clinically annotated breast cancer specimens with long-term clinical followup [30]. To examine these genes and their association with 10-year breast cancer disease-specific survival, we performed univariate Cox regression analysis on the 100 genes correlated with impaired laminin adhesion in the METABRIC dataset. The optimal cut-off for dichotomizing each gene was selected using the discovery cohort $(n=985)$ and then tested in the independent validation cohort $(n=979)$.

This analysis showed that the gene F12 is a prognostic factor (discovery cohort: hazard ratio HR $=1.65,95 \%$ confidence interval $\mathrm{CI}=1.23-2.21, p=$ $8.0 \times 10^{-4}$; validation cohort: $\mathrm{HR}=1.58, \mathrm{CI}=1.19-2.12$, $p=0.0017$, Figure 4A) while the gene STC2 is a negative prognostic factor (discovery cohort: $\mathrm{HR}=0.46, \mathrm{CI}=$ $0.34-0.61, p=5.0 \times 10^{-8}$; validation cohort: $\mathrm{HR}=0.36$, $\mathrm{CI}=0.26-0.49, p=5.6 \times 10^{-11}$, Figure $4 \mathrm{~B}$ ) for overall survival. Multivariate Cox proportional hazards analysis demonstrates that the prognostic value of these genes was independent of known prognostic variables of node status, size, grade, age, ER status and HER2 status in both cohorts (F12 discovery cohort: $\mathrm{HR}=1.47, \mathrm{CI}=1.09$ $1.97, p=0.012$; validation cohort: $\mathrm{HR}=1.53, \mathrm{CI}=1.13$ - 2.08, $p=0.0064$, STC2 discovery cohort: $\mathrm{HR}=0.71, \mathrm{CI}$ $=0.51-0.99, p=0.043$; validation cohort: $\mathrm{HR}=0.51, \mathrm{CI}$ $=0.35-0.75, p=0.00056$, Table 2).

Combining F12 and STC2 stratified patients into 4 subgroups (F12-high/STC2-low, F12-low/STC2-high, F12-high/STC2-high and F12-low/STC2-low) with F12-
low/STC2-high being associated with favourable outcome (10-year survival probability of $90.0 \%$ discovery, $90.3 \%$ validation) and F12-high/STC2-low patients having a much poorer prognosis (10-year survival probability of $68 \%$ discovery, $67.2 \%$ validation) (Figure 4C). F12 expression levels were able to further stratify the STC2low group into 2 subgroups with significantly different outcomes (discovery cohort: $\mathrm{HR}=1.45, \mathrm{CI}=1.03-2.05$, $p=0.032$; validation cohort: $\mathrm{HR}=1.57, \mathrm{CI}=1.12-2.18$, $p=0.0069$ ) (Figure 4C). Despite the gene expression signature being derived from a HER2+ panel of cell lines, we found no subtype specificity for these two genes across HER2, Luminal A, Luminal B and Basal breast cancer subtypes in the METABRIC cohort (data not shown), indicating the general applicability of the in vitro cell adhesion phenotypic screen to discover prognostic factors independent of subtypes.

\section{DISCUSSION}

Cell-ECM adhesion is a fundamental process that is important in multiple hallmarks of breast cancer, including conferring a proliferative advantage, inducing pro-survival pathways and driving cell migration and invasion [31, 32]. In this study, we employed a tumour cell-ECM interaction screen to systematically assess the cell adhesion properties in a panel of breast cancer cell lines across six different ECM components. This led to the identification of a subset of cell lines which exhibit impaired adhesion to laminin. Laminin is a major component of the BM which acts as a physical barrier that is degraded to facilitate tumour invasion. Immunohistochemistry studies on primary and metastatic breast cancer specimens have found that laminin positivity itself has no prognostic significance for disease-free and overall survival [33-35]. We show that the F12 and STC2 genes derived from a gene expression signature of impaired laminin adhesion are independent prognostic factors for overall survival in breast cancer. Specifically, patients with the F12-high/STC2-low profile found in the cells with impaired laminin adhesion, had a poorer outcome compared to those with F12-low/STC2high gene expression. Cell migration is a key determinant of cancer cell dissemination and metastasis and it has been shown that increased cell adhesion to laminin inhibits breast cancer cell migration [36-40]. In keeping with this model, the ontology analysis performed in this study showed that there is an enrichment of genes for cell motility in breast cancer cells with impaired laminin adhesion. Given that our data demonstrates that patients with a F12-high/STC-low profile have a poorer outcome, a possible hypothesis is that poor breast cancer diseasespecific survival may be the result of reduced laminin adhesion and increased tumour cell migration, leading to elevated cancer cell dissemination from the primary site.

Despite our data demonstrating that cell lines with impaired laminin adhesion were enriched in genes 
associated with cell motility, there was no correlation of laminin receptor mRNA expression levels with cell adhesion to laminin (Table 1). Laminins are a class of heterotrimeric proteins composed of $\alpha, \beta$ and $\gamma$ chains which are predominantly found in the basement membrane that separates the breast epithelial from the stroma $[41$, 42]. Breast cancer cells interact with laminins via the integrins which are heterodimeric receptors comprising an $\alpha$ and $\beta$ subunit. Multiple integrins are known to bind to laminins including the $\alpha 3 \beta 1, \alpha 6 \beta 1, \alpha 7 \beta 1$ and $\alpha 6 \beta 4$ receptors $[27,43]$. The collagen binding $\alpha 1 \beta 1, \alpha 2 \beta 1$ and $\alpha 10 \beta 1$ integrins have also been shown to bind to laminins [27]. The binding of integrins to laminins triggers the formation of a multi-protein signalling complex called the adhesome [44]. This dynamic process is known as outside-in signalling and involves the recruitment of integrin-binding and actin-binding proteins as well as kinases [45]. Prominent pathways that are activated downstream of integrin binding are the FAK, PI3K, ERK and RhoA pathways which drive a range of pathological functions including tumour cell migration and invasion $[46,47]$. Additionally, several studies report significant crosstalk between $\alpha 6 \beta 1$ and $\alpha 6 \beta 4$ integrins and HER2 in breast cancer cell lines [48, 49]. Our data shows no correlation between integrin mRNA levels and laminin adhesion which is in agreement with previous reports indicating that steady state integrin RNA expression levels are poor predictors of the cell adhesion phenotype [20]. Given that cell adhesion is mediated by specific integrin heterodimers, it is likely that future assessment of cell surface levels of integrins as measured by flow cytometry will be more predictive of ECM-cell adhesion capacity in our assays [50].

STC2 encodes for the stanniocalcin 2 protein which is a glycoprotein hormone that is decreased in cell lines with impaired laminin adhesion. This protein was first identified in bony fish and has since been shown to be ubiquitously expressed in almost all mammalian tissues where it plays a role in the regulation of calcium and phosphate transport [51]. In agreement with the poorer outcome associated with low STC2 expression presented in this study, prior reports have shown that reduced stanniocalcin 2 expression promotes breast cancer cell proliferation, migration and invasion. Stanniocalcin 2 expression is regulated by hormone signalling and an increase in stanniocalcin 2 expression levels leads to a reduction in breast cancer cell viability in vitro [52]. Overexpression of stanniocalcin 2 also suppressed breast cancer cell migration and inhibited tumorigenesis and metastasis in a xenograft model of breast cancer [53]. Consistent with our findings, in a previous study STC2 levels were analysed in 110 breast cancer cases and found to be associated with favourable prognosis in hormone receptor (HR)-positive breast cancer patients treated with adjuvant hormone therapy [54]. Similarly, another study showed in a panel of 245 breast tumours that STC2 positivity was prognostic for favourable disease-free survival [55]. Larger cohorts comprising defined stages and subtypes of breast cancer will be necessary to evaluate the prognostic potential of STC2, especially in the context of HR-positive breast cancer.

The F12 gene encodes for the plasma coagulation factor XII (FXII) which is a serine protease precursor that plays a role in the normal blood clotting process [56]. In addition to its role in blood clotting, FXII functions as a potent mitogen through the binding of the urokinase plasminogen activator receptor (UPAR) [57-59]. This leads to the activation of both the ERK1/2 and AKT pathways which promotes cell proliferation [57, 60]. Interestingly blockade of integrins $\beta 1, \alpha 3$ and $\alpha 5$ inhibited FXII induced signalling suggesting crosstalk between the UPAR and laminin and fibronectin receptor pathways [60, 61]. It is still unclear if FXII is a bona fide cancer driver but it shares remarkable similarities with the activation of UPAR by urokinase plasminogen activator (UPA), an important driver of epithelial-mesenchymal transition in breast cancer $[62,63]$. To our knowledge, there have been no clinicopathological studies performed to evaluate the prognostic value of F12 and our study is the first to demonstrate a novel association between high F12 gene expression levels and unfavourable prognosis in breast cancer. Our findings are consistent with the function of FXII as a mitogen and warrants further study of its potential role as a candidate oncogene in breast cancer.

Analysis of molecular pathways associated with impaired laminin adhesion shows an enrichment of gene sets for cytokine signalling and inflammation. Previous reports indicate that cytokines have the capacity to modulate ECM adhesion in immune cells [64-67]. For instance, pro-inflammatory cytokines TNF $\alpha, \mathrm{IFN} \alpha$ and INF $\gamma$ promote laminin adhesion while TGF $\beta 1$ had the opposing effect in microglial cells [65]. Adhesion of CD4+ $\mathrm{T}$ cells to laminin has been shown to increase in response to TNF $\alpha$ [66]. Pro- and anti-adhesive cytokine activities are less well studied in cancer cells. Treatment of colon carcinoma HT-29 cells with IL-4 and TNF $\alpha$ led to an increase in fibronectin adhesion in vitro with a corresponding decrease in lung colonizing potential in vivo [68]. In the MIA $\mathrm{PaCa} 2$ pancreatic cancer cell line, IL-1 $\beta$ reduced adhesion to laminin while IL- $1 \alpha$ increased fibronectin adhesion but impaired collagen I adhesion [69]. In another study, both IL-1 $\beta$ and TNF $\alpha$ promoted MG-63 osteosarcoma cell adhesion on laminin [70]. Our data documents a strong association between cytokine signalling, inflammation and the regulation of laminin adhesion in breast cancer cells. In view of the increasing appreciation of the role of inflammation in driving breast cancer progression and the potential for immunotherapies in this disease [71], future experimental analysis of the impact of cytokines in modulating breast cancer cell adhesion will be required to establish if this is a major contributor to tumour development. 
It should be noted that gene expression profiles from the METABRIC dataset are derived from clinical specimens composed of a heterogeneous population of different cell types, including tumour and stromal cells [72]. There may also be considerable intra-tumoural heterogeneity within tumour cell populations which is masked in population-level gene expression measurements [73]. In contrast, the expression profiles from the CCLE compendium are generated from breast cancer cell lines which are largely homogenous in nature. While we have shown that the F12/STC2 gene pair is an independent prognostic factor for breast cancer survival, given the heterogeneity inherent in clinical specimens we cannot exclude the possibility that alterations in F12 and STC2 levels may be contributed in part by stromal cells. Future work using single-cell RNA-sequencing methods may shed light on the relative contributions of tumour versus stromal cells in breast cancer prognostication [74].

One limitation of our study is that all adhesion measurements were performed on ECM coated surfaces as opposed to 3-dimensional (3D) culture systems. It is recognised that cells embedded in 3D ECM cultures better simulate the tumour microenvironment in vivo by recapitulating features such as hypoxic gradients $[75,76]$. There may be context-dependent signalling differences in 3D versus 2-dimensional (2D) cultures where cells in 3D ECM conditions may be exposed to spatial cues and tensional forces necessary to trigger integrin bidirectional signalling [76]. Notwithstanding the limitations of the simplified experimental setup of ECM coated surfaces, our study demonstrates that novel prognostic factors can still be readily identified with this approach. We anticipate that the use of more physiologically relevant models such as 3D ECM cultures is likely to lead to the identification of additional independent adhesionassociated prognosticators of breast cancer survival.

In summary, we show for the first time that the systematic analysis of cell-ECM interactions has utility in defining new prognostic factors for breast cancer diseasespecific survival. Our study also sheds light on a potential role of cytokine signalling in the regulation of cancer cell adhesion. Future analysis in a larger panel of cell lines with additional ECM substrates will ascertain the general applicability of this approach in the detection of prognostic biomarkers in other cancer types.

\section{MATERIALS AND METHODS}

\section{Cell culture}

Breast cancer cell lines were obtained from ATCC (Manassas, VI, USA). BT474, SkBr3, UACC812 and JIMT1 were grown in Dulbecco's Modified Eagle's Medium (DMEM) supplemented with $10 \%$ foetal bovine serum (FBS). ZR75.30, AU565 and HCC1954 were grown in RPMI-1640 supplemented with $10 \%$ foetal bovine serum. All cells were cultured in a $37^{\circ} \mathrm{C}$ incubator with $5 \% \mathrm{CO}_{2}$.

\section{Extracellular matrix coating}

Collagen I (rat tail; Sigma Aldrich) and collagen IV (from human placenta; Sigma Aldrich) were diluted to $20 \mathrm{ug} / \mathrm{mL}$ in $0.5 \mathrm{M}$ acetic acid, tenascin $\mathrm{C}$ (human purified; Millipore) was diluted to $5 \mathrm{ug} / \mathrm{mL}$ in $\mathrm{PBS}$, fibronectin (from human plasma; Millipore), laminin (mouse purified; Millipore) and hyaluronan (high molecular weight; R\&D Systems) were diluted to $20 \mathrm{ug} / \mathrm{mL}$ in PBS. Diluted coatings were applied to cover wells or flasks for $2 \mathrm{~h}$ at room temperature, then removed and washed with PBS. PBS was removed and cells were seeded in their appropriate media.

For assays using pairwise ECM combinations, collagen I and collagen IV were diluted to $40 \mathrm{ug} / \mathrm{mL}$ in $0.5 \mathrm{M}$ acetic acid, tenascin $\mathrm{C}$ was diluted to $10 \mathrm{ug} / \mathrm{mL}$ in PBS, and other ECM components were diluted to 40ug/ $\mathrm{mL}$ in PBS. These ECM dilutions were mixed 1:1 for each pairwise combination prior to plating. Additional concentration-matched single ECM controls were generated by further diluting single ECM components 1:1 in PBS.

\section{Cell adhesion and proliferation assays}

For 72 hour assays, cells were seeded at $2-5 \times 10^{3}$ per well (as appropriate per cell line) onto coated or uncoated 96-well CellCarrier imaging plates (Perkin Elmer). Harvest was $72 \mathrm{~h}$ post-treatment, and $8 \mathrm{~h}$ (HCC1954, SkBr3, JIMT1, AU565) or 24h (BT474, ZR75.30, UACC812) prior to harvest, 10uM BrdU (Sigma Aldrich) was added to media. To harvest, cells were fixed in $4 \%$ formaldehyde for 15 minutes, then washed $2 x$ with PBS and permeabilised with $0.25 \%$ Triton $\mathrm{X}-100$ in PBS for 10 minutes, washed $2 \mathrm{x}$ then blocked with $10 \%$ FBS in PBS. 50uL primary anti-BrdU antibody (BU20a; Affymetrix) diluted 1:1000 and RQ1 DNAse (Promega) diluted 1:200 in DNAse buffer (40mM Tris- $\mathrm{HCl}(\mathrm{pH} 8), 10 \mathrm{mM} \mathrm{MgSO}_{4}$, $1 \mathrm{mM} \mathrm{CaCl}_{2}$ ) was added to each well and incubated at $37^{\circ} \mathrm{C}$ for $3 \mathrm{~h}$. Wells were washed $2 \mathrm{x}$ TPBS, then secondary AlexaFluor 488 goat anti-mouse antibody (Life Technologies) and Hoechst 33342 (Tocris) were added $1: 1000$ and 1:2000 respectively in 10\% FBS in PBS for $1 \mathrm{~h}$. Plates were washed $2 \mathrm{x}$ in TPBS, then plates were imaged on an Operetta high-content imager (Perkin Elmer) using a 10x High NA lens. Images were analysed using Harmony software (Perkin Elmer), and BrdU positivity was defined as number of Hoechst-stained nuclei also showing 488 stain positivity $>2$ times background staining. 


\section{Gene expression analysis}

We obtained the microarray gene expression data from the Cancer Cell Line Encyclopaedia (GSE36133). These cell lines were profiled using Affymetrix HGU133 Plus 2.0 microarrays. Raw CEL files for these cell lines were normalized using Robust Multiarray Average (RMA) approach in Affymetrix Power Tools (APT). Gene Set Enrichment Analysis (GSEA) software version 2.2.2 from the Broad Institute [77] was used to identify genes and pathways enriched in cell lines with impaired laminin adhesion. Our input file contained expression data for 21,010 genes and 7 cell lines. We used 1000 gene set permutations for the analysis and pathways with nominal $P$ values $<0.05$ were considered significant. We used the 522 pathways in the curated gene sets $(\mathrm{C} 2 . \mathrm{V} 1)$ collection from MSigDB. Gene sets with less than 10 genes were excluded from our analysis. GSEA software was also used to identify 50 genes with the strongest positive correlations and 50 genes with the strongest negative correlations to the impaired laminin adhesion phenotype. Statistical significance of gene correlations to the impaired laminin adhesion phenotype was determined using the HolmSidak method which corrects for multiple comparisons using Graphpad Prism software. $P<0.05$ was deemed significant.

Gene expression data of 17,653 genes from the METABRIC study were profiled using Illumina HT-12 v3 microarray. The top 50 genes that were positively and negatively correlated with impaired laminin adhesion in the cell line panel were subjected to further analysis. As outlined in the METABRIC study, the discovery and validation cohorts were defined by hospital sites, for further details of clinical specimens please refer to [30]. Survival analysis was performed with breast-cancerspecific 10-year survival data. The Kaplan-Meier estimator was used, and the log-rank test was performed to test differences among groups. For univariate and multivariate analysis, the Cox proportional hazards regression model was fitted, and $95 \%$ confidence intervals computed to determine prognostic values; log-rank test $p<0.05$ was considered significant. In the discovery set, a search for optimal threshold for dichotomizing gene expression data was carried out by searching stepwise from 40 to 60 percentiles at an interval of 5. The cut-offs that displayed the highest prognostic significance with log-rank test were selected and used for the validation cohort. Multivariate survival analysis was carried out in both patient cohorts using gene expression data, node status, ER status, HER2 status, age, tumour size and grade.

\section{Real-time quantitative PCR}

Total RNA was isolated from cultured cell lines using Trizol reagent (Life Technologies), treated with
DNase I (Promega) and reverse transcribed into cDNA with SuperScript III First-strand Synthesis kit (Life Technologies). qPCR was carried out using SYBR green PCR master mix (Life Technologies) on an Applied Biosystems 7900HT instrument. Data were normalized against $\beta$-actin levels and analysed using Applied Biosystems RQ manager software. The gene-specific primers used are listed in Supplemental Table 4.

\section{CONFLICTS OF INTEREST}

The authors have no conflicts to declare.

\section{FUNDING}

This work was supported by grants from the Institute of Cancer Research (ICR), Cancer Research UK (C36478/ A19281) and Breast Cancer Now (2014NovPR360 and 2013NovPhD185) to PHH, a Breast Cancer Now Scientific Fellowship (SF01May2011) to RCN, a National Institutes of Health Ruth L. Kirschstein National Research Service Award (T32CA17468) to KAR, David F. and Margaret T. Grohne Family Foundation to ACT and Wellcome Trust $105104 / \mathrm{Z} / 14 / \mathrm{Z}$ to $\mathrm{YY}$.

\section{REFERENCES}

1. Lu P, Weaver VM and Werb Z. The extracellular matrix: a dynamic niche in cancer progression. J Cell Biol. 2012; 196:395-406.

2. Ma XJ, Dahiya S, Richardson E, Erlander M and Sgroi DC. Gene expression profiling of the tumor microenvironment during breast cancer progression. Breast Cancer Res. 2009; 11:R7.

3. Geiger B and Yamada KM. Molecular architecture and function of matrix adhesions. Cold Spring Harb Perspect Biol. 2011; 3 .

4. Robertson J, Jacquemet G, Byron A, Jones MC, Warwood S, Selley JN, Knight D, Humphries JD and Humphries MJ. Defining the phospho-adhesome through the phosphoproteomic analysis of integrin signalling. Nat Commun. 2015; 6:6265.

5. Lyons TR, O'Brien J, Borges VF, Conklin MW, Keely PJ, Eliceiri KW, Marusyk A, Tan AC and Schedin P. Postpartum mammary gland involution drives progression of ductal carcinoma in situ through collagen and COX-2. Nat Med. 2011; 17:1109-1115.

6. Provenzano PP, Inman DR, Eliceiri KW, Knittel JG, Yan L, Rueden CT, White JG and Keely PJ. Collagen density promotes mammary tumor initiation and progression. BMC Med. 2008; 6:11.

7. Cox TR, Bird D, Baker AM, Barker HE, Ho MW, Lang $\mathrm{G}$ and Erler JT. LOX-mediated collagen crosslinking is responsible for fibrosis-enhanced metastasis. Cancer Res. 2013; 73:1721-1732. 
8. Chia J, Kusuma N, Anderson R, Parker B, Bidwell B, Zamurs L, Nice E and Pouliot N. Evidence for a role of tumor-derived laminin-511 in the metastatic progression of breast cancer. Am J Pathol. 2007; 170:2135-2148.

9. Rowe RG and Weiss SJ. Breaching the basement membrane: who, when and how? Trends Cell Biol. 2008; 18:560-574.

10. Ishihara A, Yoshida T, Tamaki H and Sakakura T. Tenascin expression in cancer cells and stroma of human breast cancer and its prognostic significance. Clin Cancer Res. 1995; 1:1035-1041.

11. Fernandez-Garcia B, Eiro N, Marin L, GonzalezReyes S, Gonzalez LO, Lamelas ML and Vizoso FJ. Expression and prognostic significance of fibronectin and matrix metalloproteases in breast cancer metastasis. Histopathology. 2014; 64:512-522.

12. Yao ES, Zhang H, Chen YY, Lee B, Chew K, Moore D and Park C. Increased betal integrin is associated with decreased survival in invasive breast cancer. Cancer Res. 2007; 67:659-664.

13. Planche A, Bacac M, Provero P, Fusco C, Delorenzi M, Stehle JC and Stamenkovic I. Identification of prognostic molecular features in the reactive stroma of human breast and prostate cancer. PLoS One. 2011; 6:e18640.

14. Chang HY, Nuyten DS, Sneddon JB, Hastie T, Tibshirani R, Sorlie T, Dai H, He YD, van't Veer LJ, Bartelink H, van de Rijn M, Brown PO and van de Vijver MJ. Robustness, scalability, and integration of a wound-response gene expression signature in predicting breast cancer survival. Proc Natl Acad Sci U S A. 2005; 102:3738-3743.

15. Bianchini G, Qi Y, Alvarez RH, Iwamoto T, Coutant C, Ibrahim NK, Valero V, Cristofanilli M, Green MC, Radvanyi L, Hatzis C, Hortobagyi GN, Andre F, Gianni L, Symmans WF and Pusztai L. Molecular anatomy of breast cancer stroma and its prognostic value in estrogen receptor-positive and -negative cancers. J Clin Oncol. 2010; 28:4316-4323.

16. Finak G, Bertos N, Pepin F, Sadekova S, Souleimanova M, Zhao H, Chen H, Omeroglu G, Meterissian S, Omeroglu A, Hallett M and Park M. Stromal gene expression predicts clinical outcome in breast cancer. Nat Med. 2008; 14:518527.

17. Naba A, Clauser KR, Hoersch S, Liu H, Carr SA and Hynes RO. The matrisome: in silico definition and in vivo characterization by proteomics of normal and tumor extracellular matrices. Mol Cell Proteomics. 2012; 11:M111 014647.

18. Multhaupt HA, Leitinger B, Gullberg D and Couchman JR. Extracellular matrix component signaling in cancer. Adv Drug Deliv Rev. 2015.

19. Xu H, Bihan D, Chang F, Huang PH, Farndale RW and Leitinger B. Discoidin domain receptors promote alpha1beta1- and alpha2beta1-integrin mediated cell adhesion to collagen by enhancing integrin activation. PLoS
One. 2012; 7:e52209.

20. Reticker-Flynn NE, Malta DF, Winslow MM, Lamar JM, Xu MJ, Underhill GH, Hynes RO, Jacks TE and Bhatia SN. A combinatorial extracellular matrix platform identifies cell-extracellular matrix interactions that correlate with metastasis. Nat Commun. 2012; 3:1122.

21. Desgrosellier JS and Cheresh DA. Integrins in cancer: biological implications and therapeutic opportunities. Nat Rev Cancer. 2010; 10:9-22.

22. Wetterskog D, Shiu KK, Chong I, Meijer T, Mackay A, Lambros M, Cunningham D, Reis-Filho JS, Lord CJ and Ashworth A. Identification of novel determinants of resistance to lapatinib in ERBB2-amplified cancers. Oncogene. 2014; 33:966-976.

23. Shiu KK, Wetterskog D, Mackay A, Natrajan R, Lambros M, Sims D, Bajrami I, Brough R, Frankum J, Sharpe R, Marchio C, Horlings H, Reyal F, van der Vijver M, Turner $\mathrm{N}$, Reis-Filho JS, et al. Integrative molecular and functional profiling of ERBB2-amplified breast cancers identifies new genetic dependencies. Oncogene. 2014; 33:619-631.

24. Slamon DJ, Clark GM, Wong SG, Levin WJ, Ullrich A and McGuire WL. Human breast cancer: correlation of relapse and survival with amplification of the HER-2/neu oncogene. Science. 1987; 235:177-182.

25. Oskarsson T. Extracellular matrix components in breast cancer progression and metastasis. Breast. 2013; 22 Suppl 2:S66-72.

26. Payne LS and Huang PH. The pathobiology of collagens in glioma. Mol Cancer Res. 2013; 11:1129-1140.

27. Humphries JD, Byron A and Humphries MJ. Integrin ligands at a glance. J Cell Sci. 2006; 119:3901-3903.

28. Barretina J, Caponigro G, Stransky N, Venkatesan K, Margolin AA, Kim S, Wilson CJ, Lehar J, Kryukov GV, Sonkin D, Reddy A, Liu M, Murray L, Berger MF, Monahan JE, Morais P, et al. The Cancer Cell Line Encyclopedia enables predictive modelling of anticancer drug sensitivity. Nature. 2012; 483:603-607.

29. Pouliot N and Kusuma N. Laminin-511: a multi-functional adhesion protein regulating cell migration, tumor invasion and metastasis. Cell Adh Migr. 2013; 7:142-149.

30. Curtis C, Shah SP, Chin SF, Turashvili G, Rueda OM, Dunning MJ, Speed D, Lynch AG, Samarajiwa S, Yuan Y, Graf S, Ha G, Haffari G, Bashashati A, Russell R, McKinney $\mathrm{S}$, et al. The genomic and transcriptomic architecture of 2,000 breast tumours reveals novel subgroups. Nature. 2012; 486:346-352.

31. Polyak K and Kalluri R. The role of the microenvironment in mammary gland development and cancer. Cold Spring Harb Perspect Biol. 2010; 2:a003244.

32. Pickup MW, Mouw JK and Weaver VM. The extracellular matrix modulates the hallmarks of cancer. EMBO Rep. 2014; 15:1243-1253.

33. Pellegrini $\mathrm{R}$, Martignone $\mathrm{S}$, Tagliabue E, Belotti D, Bufalino R, Cascinelli N, Menard S and Colnaghi MI. 
Prognostic significance of laminin production in relation with its receptor expression in human breast carcinomas. Breast Cancer Res Treat. 1995; 35:195-199.

34. Molino A, Pedersini R, Micciolo R, Frisinghelli M, Giovannini M, Pavarana M, Santo A, Colato C, Piubello Q and Cetto GL. Prognostic significance of laminin, laminin receptor, and bone marrow micrometastases in breast cancer patients: are these markers of aggressive behavior and metastatic potential? Appl Immunohistochem Mol Morphol. 2003; 11:311-318.

35. Yao K, Tan J, Ye P, Wang K, Xu W, ShenTu X and Tang X. Integrin betal-mediated signaling is involved in transforming growth factor-beta2-promoted migration in human lens epithelial cells. Mol Vis. 2007; 13:1769-1776.

36. Lindberg K, Strom A, Lock JG, Gustafsson JA, Haldosen LA and Helguero LA. Expression of estrogen receptor beta increases integrin alpha1 and integrin betal levels and enhances adhesion of breast cancer cells. J Cell Physiol. 2010; 222:156-167.

37. Ivanova IA, Vermeulen JF, Ercan C, Houthuijzen JM, Saig FA, Vlug EJ, van der Wall E, van Diest PJ, Vooijs M and Derksen PW. FER kinase promotes breast cancer metastasis by regulating alpha6- and beta1-integrin-dependent cell adhesion and anoikis resistance. Oncogene. 2013; 32:55825592.

38. Li Y, Francia G and Zhang JY. p62/IMP2 stimulates cell migration and reduces cell adhesion in breast cancer. Oncotarget. 2015; 6:32656-32668. doi: 10.18632/ oncotarget.5328.

39. Sureshbabu A, Okajima H, Yamanaka D, Tonner E, Shastri S, Maycock J, Szymanowska M, Shand J, Takahashi S, Beattie J, Allan G and Flint D. IGFBP5 induces cell adhesion, increases cell survival and inhibits cell migration in MCF-7 human breast cancer cells. J Cell Sci. 2012; 125:1693-1705

40. Friedl P and Wolf K. Tumour-cell invasion and migration: diversity and escape mechanisms. Nat Rev Cancer. 2003; 3:362-374.

41. Aumailley M. The laminin family. Cell Adh Migr. 2013; 7:48-55.

42. Nistico P, Di Modugno F, Spada S and Bissell MJ. beta1 and beta4 integrins: from breast development to clinical practice. Breast Cancer Res. 2014; 16:459.

43. Stipp CS. Laminin-binding integrins and their tetraspanin partners as potential antimetastatic targets. Expert Rev Mol Med. 2010; 12:e3.

44. Byron A and Frame MC. Adhesion protein networks reveal functions proximal and distal to cell-matrix contacts. Curr Opin Cell Biol. 2016; 39:93-100.

45. Horton ER, Byron A, Askari JA, Ng DH, Millon-Fremillon A, Robertson J, Koper EJ, Paul NR, Warwood S, Knight D, Humphries JD and Humphries MJ. Definition of a consensus integrin adhesome and its dynamics during adhesion complex assembly and disassembly. Nat Cell Biol.
$2015 ; 17: 1577-1587$.

46. Stewart RL and O'Connor KL. Clinical significance of the integrin alpha6beta4 in human malignancies. Lab Invest. 2015; 95:976-986.

47. Guan X. Cancer metastases: challenges and opportunities. Acta Pharm Sin B. 2015; 5:402-418.

48. Falcioni R, Antonini A, Nistico P, Di Stefano S, Crescenzi M, Natali PG and Sacchi A. Alpha 6 beta 4 and alpha 6 beta 1 integrins associate with ErbB-2 in human carcinoma cell lines. Exp Cell Res. 1997; 236:76-85.

49. Tagliabue E, Ardini E, Pellegrini R, Campiglio M, Bufalino $\mathrm{R}$, Jeschke M, Groner B, Colnaghi MI and Menard S. Laminin activates the p185HER2 oncoprotein and mediates growth inhibition of breast carcinoma cells. Br J Cancer. 1996; 74:1427-1433.

50. Taherian A, Li X, Liu Y and Haas TA. Differences in integrin expression and signaling within human breast cancer cells. BMC Cancer. 2011; 11:293.

51. Yeung BH, Law AY and Wong CK. Evolution and roles of stanniocalcin. Mol Cell Endocrinol. 2012; 349:272-280.

52. Raulic S, Ramos-Valdes Y and DiMattia GE. Stanniocalcin 2 expression is regulated by hormone signalling and negatively affects breast cancer cell viability in vitro. $\mathrm{J}$ Endocrinol. 2008; 197:517-529.

53. Hou J, Wang Z, Xu H, Yang L, Yu X, Yang Z, Deng Y, Meng J, Feng Y, Guo X and Yang G. Stanniocalicin 2 suppresses breast cancer cell migration and invasion via the PKC/claudin-1-mediated signaling. PLoS One. 2015; 10:e0122179.

54. Yamamura J, Miyoshi Y, Tamaki Y, Taguchi T, Iwao K, Monden M, Kato K and Noguchi S. mRNA expression level of estrogen-inducible gene, alpha 1-antichymotrypsin, is a predictor of early tumor recurrence in patients with invasive breast cancers. Cancer Sci. 2004; 95:887-892.

55. Esseghir S, Kennedy A, Seedhar P, Nerurkar A, Poulsom $\mathrm{R}$, Reis-Filho JS and Isacke CM. Identification of NTN4, TRA1, and STC2 as prognostic markers in breast cancer in a screen for signal sequence encoding proteins. Clin Cancer Res. 2007; 13:3164-3173.

56. Stavrou E and Schmaier AH. Factor XII: what does it contribute to our understanding of the physiology and pathophysiology of hemostasis \& thrombosis. Thromb Res. 2010; 125:210-215.

57. Schmeidler-Sapiro KT, Ratnoff OD and Gordon EM. Mitogenic effects of coagulation factor XII and factor XIIa on HepG2 cells. Proc Natl Acad Sci U S A. 1991; 88:43824385.

58. Gordon EM, Venkatesan N, Salazar R, Tang H, SchmeidlerSapiro K, Buckley S, Warburton D and Hall FL. Factor XII-induced mitogenesis is mediated via a distinct signal transduction pathway that activates a mitogen-activated protein kinase. Proc Natl Acad Sci U S A. 1996; 93:21742179. 
59. Mahdi F, Madar ZS, Figueroa CD and Schmaier AH. Factor XII interacts with the multiprotein assembly of urokinase plasminogen activator receptor, $\mathrm{gC} 1 \mathrm{qR}$, and cytokeratin 1 on endothelial cell membranes. Blood. 2002; 99:3585-3596.

60. LaRusch GA, Mahdi F, Shariat-Madar Z, Adams G, Sitrin RG, Zhang WM, McCrae KR and Schmaier AH. Factor XII stimulates ERK1/2 and Akt through uPAR, integrins, and the EGFR to initiate angiogenesis. Blood. 2010; 115:51115120 .

61. Wei Y, Czekay RP, Robillard L, Kugler MC, Zhang F, Kim KK, Xiong JP, Humphries MJ and Chapman HA. Regulation of alpha5beta1 integrin conformation and function by urokinase receptor binding. J Cell Biol. 2005; 168:501-511.

62. Smith HW and Marshall CJ. Regulation of cell signalling by uPAR. Nat Rev Mol Cell Biol. 2010; 11:23-36.

63. Lester RD, Jo M, Montel V, Takimoto S and Gonias SL. UPAR induces epithelial-mesenchymal transition in hypoxic breast cancer cells. J Cell Biol. 2007; 178:425-436.

64. Zeltzer E, Bernheim J, Korzets Z, Zeeli D, Rathaus M, Mekori YA and Hershkoviz R. Diminished chemokine and cytokine-induced adhesion of CD4+ T cells to extracellular matrix ligands in patients with end-stage renal failure. Isr Med Assoc J. 2000; 2:282-286.

65. Milner R and Campbell IL. Cytokines regulate microglial adhesion to laminin and astrocyte extracellular matrix via protein kinase C-dependent activation of the alpha6beta1 integrin. J Neurosci. 2002; 22:1562-1572.

66. Hershkoviz R, Goldkorn I and Lider O. Tumour necrosis factor-alpha interacts with laminin and functions as a proadhesive cytokine. Immunology. 1995; 85:125-130.

67. Strobel ES, Mobest D, von Kleist S, Dangel M, Ries S, Mertelsmann R and Henschler R. Adhesion and migration are differentially regulated in hematopoietic progenitor cells by cytokines and extracellular matrix. Blood. 1997; 90:3524-3532.

68. Herzberg F, Schoning M, Schirner M, Topp M, Thiel E and Kreuser ED. IL-4 and TNF-alpha induce changes in integrin expression and adhesive properties and decrease the lungcolonizing potential of HT-29 colon carcinoma cells. Clin Exp Metastasis. 1996; 14:165-175.
69. Stefani AL, Basso D, Panozzo MP, Greco E, Mazza S, Zancanaro F, De Franchis G and Plebani M. Cytokines modulate MIA PaCa 2 and CAPAN-1 adhesion to extracellular matrix proteins. Pancreas. 1999; 19:362-369.

70. Santala P and Heino J. Regulation of integrin-type cell adhesion receptors by cytokines. J Biol Chem. 1991; 266:23505-23509.

71. Kroemer G, Senovilla L, Galluzzi L, Andre F and Zitvogel L. Natural and therapy-induced immunosurveillance in breast cancer. Nat Med. 2015; 21:1128-1138.

72. Natrajan R, Sailem H, Mardakheh FK, Arias Garcia M, Tape CJ, Dowsett M, Bakal C and Yuan Y. Microenvironmental Heterogeneity Parallels Breast Cancer Progression: A Histology-Genomic Integration Analysis. PLoS Med. 2016; 13:e1001961.

73. Martelotto LG, Ng CK, Piscuoglio S, Weigelt B and ReisFilho JS. Breast cancer intra-tumor heterogeneity. Breast Cancer Res. 2014; 16:210.

74. Wu AR, Neff NF, Kalisky T, Dalerba P, Treutlein B, Rothenberg ME, Mburu FM, Mantalas GL, Sim S, Clarke MF and Quake SR. Quantitative assessment of single-cell RNA-sequencing methods. Nat Methods. 2014; 11:41-46.

75. Kenny PA. Three-dimensional extracellular matrix culture models of EGFR signalling and drug response. Biochem Soc Trans. 2007; 35:665-668.

76. Kenny PA, Lee GY, Myers CA, Neve RM, Semeiks JR, Spellman PT, Lorenz K, Lee EH, Barcellos-Hoff MH, Petersen OW, Gray JW and Bissell MJ. The morphologies of breast cancer cell lines in three-dimensional assays correlate with their profiles of gene expression. Mol Oncol. 2007; 1:84-96.

77. Subramanian A, Tamayo P, Mootha VK, Mukherjee S, Ebert BL, Gillette MA, Paulovich A, Pomeroy SL, Golub TR, Lander ES and Mesirov JP. Gene set enrichment analysis: a knowledge-based approach for interpreting genome-wide expression profiles. Proc Natl Acad Sci U S A. $2005 ; 102: 15545-15550$. 